\title{
A questionnaire-based survey among clinicians and postgraduates regarding knowledge, awareness and practice of p-drug in Government General Hospital, Rangaraya Medical College, Kakinada
}

\author{
Grandhi Ramya Kanthi, Usha Kiran Prayaga*
}

\begin{abstract}
Department of pharmacology, Rangaraya medical college, Dr. NTR University of health sciences, Opposite government general hospital, Kakinada ,Andhra Pradesh,India
\end{abstract}

Received: 30 October 2019

Revised: 16 December 2019

Accepted: 17 December 2019

\section{*Correspondence:}

Dr. Usha Kiran Prayaga,

Email: ramyakanthidr@gmail.com

Copyright: (c) the author(s), publisher and licensee Medip Academy. This is an open-access article distributed under the terms of the Creative Commons Attribution Non-Commercial License, which permits unrestricted non-commercial use, distribution, and reproduction in any medium, provided the original work is properly cited.

\begin{abstract}
Background: P-drug is a personal or preferred or priority choice drug of a clinician. The aim of the study is to evaluate knowledge, awareness, practice of p-drug which helps the clinician to prescribe drugs rationally.

Methods: The study was a prospective cross-sectional pre-validated questionnaire-based study conducted in Government General Hospital, Rangaraya Medical College, Kakinada. During the study period a total of 300 members were enrolled and instructed to fill the questionnaire forms. These filled forms were collected and data were analyzed.

Results: Out of 300 members, 240 filled the questionnaire, and these forms were evaluated. Among them $16.6 \%$ were aware of p-drug, 27.5\% were aware of P treatment, 32.5\% were not including FDC's in their p drug list, $28.33 \%$ were aware of advantages of prescribing P drug and $82 \%$ felt that teaching programs were needed for preparing p drug list. Conclusions: For promoting and achieving rational use of medicine, $\mathrm{P}$ drug concept is one of the milestones. As few were aware of $p$-drug concept, institutional teaching review board should conduct teaching programs regarding $p$ drug concept.
\end{abstract}

Keywords: Fixed dose combination, P-drug, Rational use of medicine

\section{INTRODUCTION}

Alexandrian physician, Herophilus, in 300 B.C stated that "Medicines are nothing in themselves, but are the very hands of God if employed with reason and prudence". ${ }^{2}$ As per the WHO (1985), the definition of rational use of medicines - "Patients receive medications appropriate to their clinical needs, in doses that meet their requirements, for an adequate period of time, and at the lowest cost to them and their community. ${ }^{2}$ It was reported worldwide that, more than $50 \%$ of all medicines are prescribed, dispensed, or sold inappropriately, while $50 \%$ of patients fail to take them correctly. ${ }^{3}$ They are several reasons which may contribute to irrational use of drugs like lack of regular facilities which provide proper information about currently used drugs, lack of appropriate training of medical graduates during training, not sparing much time to patients, polypharmacy, absence of well-managed drug regulatory authorities, promotional activities. ${ }^{1}$ As prescribing is a challenging task which is based on scientific evidence requires knowledge of essential medicine, rational use of medicine and personal drugs ( $\mathrm{p}$-drug). According to WHO the selection of the drug should be based on a logical process 
including comprehensive and objective information. ${ }^{4} \mathrm{P}$ drugs are drugs chosen to prescribe regularly, and with which you were familiar. They are your priority choice for given medical indications. P-drug concept is not just the name of a pharmacological substance; it also includes the dosage form, dosage schedule and duration of treatment. ${ }^{5}$ They differ from country to country, doctors to doctors, because of varying availability and cost of drugs, different national formularies and essential drug lists, medical culture, and individual interpretation of information. ${ }^{5,6}$ P-drugs enable clinicians to avoid repeated search for a good drugs in daily practice and by using them regularly, will help them to know their effects and side effects thoroughly, which will obviously benefit the patient. According to this WHO guideline the selection of the drug should be based on a logical, deductive process including comprehensive and objective information. For personalized prescription, clinicians need to consider some factors like drug factors, prescriber factors, and patient factors. ${ }^{4}$ Some of the practicing physicians admitted relying on information provided by medical representatives. P-Drug should never be the one that has been indicated by clinical features, senior doctors or of course by sales representatives. ${ }^{7,8}$ Making use of 6STEP criteria helps the physician to develop rational therapeutic plan for an individual patient. ${ }^{4}$ The 6 step criteria is as follows

- Define the diagnosis

- Specify the therapeutic objectives

- Make an inventory of the effective group of drugs

- Choose an effective group according to the criteria

- Choose a p-drug

- Determine the monitoring parameters or follow-up.

The rationale behind this study is they are many studies focused on training medical students with p-drug selection but fewer studies focused on clinicians and postgraduates, as postgraduates are the future budding practioners focus was more towards them.

\section{METHODS}

After getting approval from the institutional ethics committee, total 300 members out of which 200 were postgraduates and 100 were clinicians provided with prevalidated questionnaire. The questionnaire was designed in such a way that some questions are focussed on knowledge, some on awareness and some on practice. The clinicians and postgraduates are requested to fill the questionnaire after getting back the filled forms, they were provided with a pamphlet containing basic information about p-drug.

This is a prospective cross-sectional pre-validated questionnaire-based study conducted at Government General Hospital, Rangaraya Medical College, Kakinada during a period of two months (July 2018- August 2018).
200 postgraduates and 100 clinicians were included in the study.

Those who are not willing to participate in the study and those who didn't return the forms in stipulated time were excluded from the study.

Table 1: Questionnaire regarding knowledge and awareness of $\mathbf{P}$ - drug.

\begin{tabular}{|ll|}
\hline $\begin{array}{l}\text { S. } \\
\text { no. }\end{array}$ & $\mathbf{1} \quad \mathbf{2} \quad 3$ \\
\hline 1. & $\begin{array}{l}\text { Do you know about rational use of } \\
\text { medicine? }\end{array}$ \\
\hline 2. & Are you aware of the term P- drug? \\
\hline 3. & $\begin{array}{l}\text { Do you know about } \\
\text { p-treatment? }\end{array}$ \\
\hline 4. & $\begin{array}{l}\text { Are you aware of STEP criteria for } \\
\text { the selection of P- drug? }\end{array}$ \\
\hline
\end{tabular}

1. I have never heard, 2. I think I know this, 3. I know this very well.

Table 2: Questionnaire regarding knowledge, awareness and practise regarding $\mathbf{P}$-drug.

\begin{tabular}{|ll|}
\hline $\begin{array}{l}\text { S. } \\
\text { no. }\end{array}$ & $\mathbf{1} \quad \mathbf{2} \quad \mathbf{3}$ \\
\hline 1. & Is P-drug significant? \\
\hline 2. & $\begin{array}{l}\text { Have you prepared p-drug list at } \\
\text { work? }\end{array}$ \\
\hline 3. & Is P-drug list same everywhere? \\
\hline 4. & $\begin{array}{l}\text { Do you include fixed-dose } \\
\text { combinations in your }\end{array}$ \\
\hline 5. & $\begin{array}{l}\text { Are you aware of the advantages of } \\
\text { using P-drug for prescription? }\end{array}$ \\
\hline
\end{tabular}

1. Yes, 2. No, 3. No idea.

Table 3: Question regarding practise of P-drug.

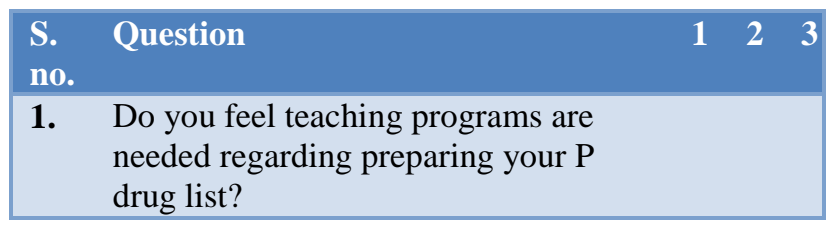

1. Disagree, 2. Agree, 3. Neutral.

\section{RESULTS}

Out of 300 members, 25 members took forms but didn't return, 35 members filled in completely, so finally 240 forms were only evaluated for results. Among 240 members the responses were recorded as follows the percentage of persons aware of rational use of medicine was $41.6 \%, 56.6 \%$ were unaware of term P-drug, $60 \%$ have no knowledge about p-treatment, $63.3 \%$ were unaware of STEP criteria which are used for P-drug selection. 


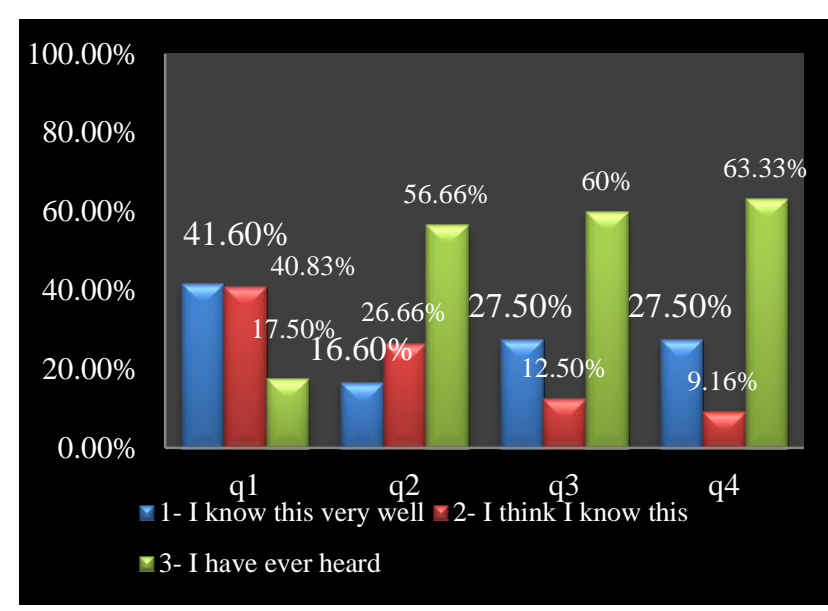

Figure 1: Response rates for questionnaire regarding knowledge and awareness of p-drug.

In Table 2 the response rates were as follows, $42.5 \%$ have no idea whether p-drug is significant or not, $50.8 \%$ haven't prepared p-drug at their work, $40.8 \%$ were not aware of advantages of using P-drug.

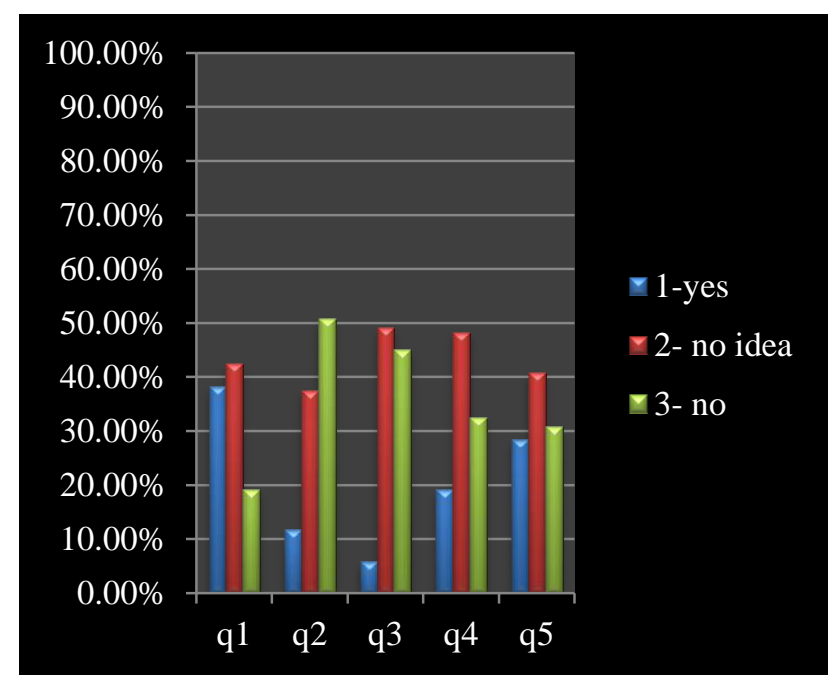

Figure 2: Response rates for questionnaire regarding knowledge, awareness and practise regarding p-drug.

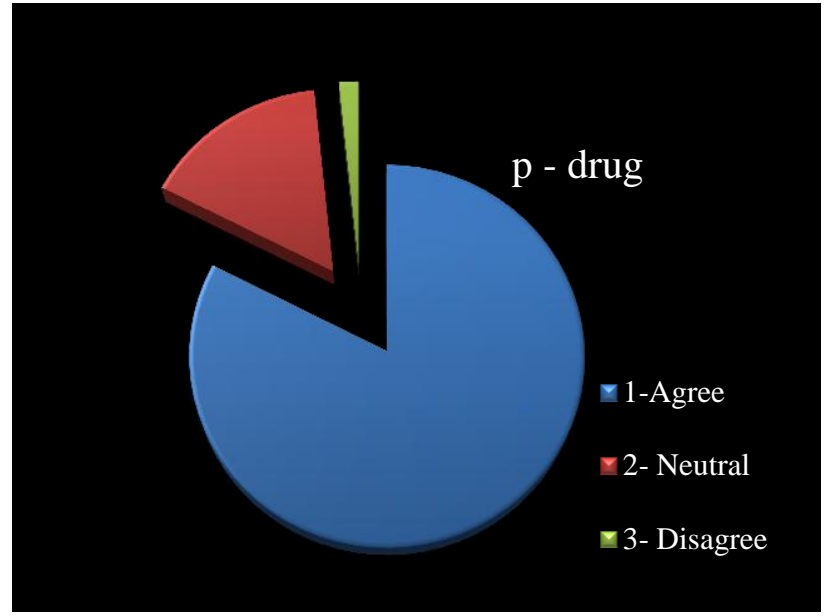

Figure 3: Response rate for p-drug teaching programs.

\section{DISCUSSION}

The present study evaluates knowledge, awareness, practice of p-drug among clinicians and postgraduates in the government general hospital. Knowledge indicates understanding of a given subject. Attitude is feelings towards this subject and any preconceived ideas. Applying their knowledge and attitude into actions constitute practice. Assessing knowledge on p-drug helps in promoting rational use of medicine as it is one of the contributors towards rationalization. In present study $42 \%$ were aware of rational use of medicines but only $16.6 \%$ were aware of term p-drug, $60 \%$ were unaware of $p$ treatment and $63 \%$ were unaware of STEP criteria in selection of p-drug. The findings are similar to previous study conducted by Bajait et al, where $35 \%$ were aware of term p-drug 9 and in study conducted by Dakhale et al, $32 \%$ were aware of term p-drug10, whereas in Tanuja et al, $63 \%$ were aware of term p-drug. ${ }^{11}$ In this study coming to knowledge about advantages of using p-drug only $28 \%$ knew about this whereas in studies conducted by Ganesh et al, and Tanuja et al, $15 \%$ knew the benefits of using pdrug. ${ }^{10,11}$ and in Bajait.et al, $9 \%$ knew the advantages of using p-drug. ${ }^{9}$

Table 1: Comparison between present study and previous studies about $\mathbf{P}$ drug.

\begin{tabular}{|lllll|}
\hline Study & $\begin{array}{l}\text { Awareness of p- } \\
\text { drug }(\boldsymbol{\%})\end{array}$ & $\begin{array}{l}\text { Advantages of using p- } \\
\text { drug }(\boldsymbol{\%})\end{array}$ & $\begin{array}{l}\text { FDC prescription } \\
(\boldsymbol{\%})\end{array}$ & $\begin{array}{l}\text { Training } \\
\text { programs (\%) }\end{array}$ \\
\hline Tanuja et al $^{\mathbf{1 1}}$ & 63.2 & 15.6 & 6.1 & 87.7 \\
\hline Bajait et al $^{\mathbf{3}}$ & 35 & 9 & - & - \\
\hline $\begin{array}{l}\text { Dakhale et } \\
\text { al }^{\mathbf{1 0}}\end{array}$ & 32 & 15 & - & - \\
\hline Present study & 42 & 28.3 & 19.16 & 82 \\
\hline
\end{tabular}

Coming to inclusion of FDC in p-drug list in our study only $19 \%$ says that we can include whereas in Tanuja et al, only $6 \%$ agrees it. ${ }^{11}$ In implementation of teaching programs regarding preparation of p-drug list $82 \%$ in our study says that they are to be implemented, similar findings were also found in Tanuja et al, study also. ${ }^{11}$ The limitations of this present study are we didn't include private practitioners in this town and undergraduate students in this institutes who attend clinics. 


\section{CONCLUSION}

The majority of the practitioners were aware of the rational use of medicine. But knowledge regarding $\mathrm{p}$-drug concept, p-treatment, significance of p-drug, inclusion of FDC in p-drug list, advantages of using p-drug in prescription was limited. As postgraduates are the future practitioners they should be aware of this. In view of promoting it institutional teaching review board should conduct teaching programs on p-drug. Similar studies should be performed at other medical colleges, district hospitals and health care centres, so that problems in knowledge, attitude and practice of rational use of medicine can be identified and appropriate corrective measures can be taken which will help in improving the quality of health care.

\section{ACKNOWLEDGEMENTS}

I sincerely acknowledge my parents Mr. G .Soma Raju and Mrs. Chandra kumari for their valuable support. I thank my guide professor and HOD Dr. Usha Kiran. P MD DM, Department of Pharmacology for his guidance and support in the study. I am happy to thank my friends (Rupa, Vamsi, Sweta, Preethi, Kauser) for giving support. I would like to thank all postgraduates and clinicians in Rangaraya Medical College for their participation in the study.

Funding: No funding sources Conflict of interest: None declared

Ethical approval: The study was approved by the Institutional Ethics Committee

\section{REFERENCES}

1. Ambwani S, Mathur AK. Rational drug Use. Health Administrator. 2017;19:5-7.

2. WHO Policy Perspectives on Medicine-Promoting rational use of medicines: core components (pg. 1), 2002 Available from: WHO Model Formulary. Geneva: WHO press; 2004.3.
3. World Health Organization: Selection and rational use of medicines. Available at: http://www.who.int/mediacentre/factsheets/fs338/en/. Accessed on 15 August 2016.

4. Rissmann R, Dubois EA, Franson KL, Cohen AF. Concept-based learning of personalized prescribing. British J clin pharmacol. 2012;74(4):589-96.

5. Medhi B, Advanced Pharmacology. p-Drug Concept. 2004: 222-225.

6. Goodman \& Gilman. The Pharmacological Basis of Therapeutics. New York: McMillan Publications Co; 1992: 8.

7. Parmar DM, Jadav SP. The concept of personal drugs in the undergraduate pharmacology practical curriculum. Ind J Pharmacol. 2007;39(3):165.

8. Andrea AD, Saravanakumar M., Vijai Anandh P. To evaluate the awareness and P- DRUG selection among general practitionersin a rural area of Tamil Nadu- a questionnaire based study. Int $\mathbf{J}$ Res Pharmacol Pharmacotherapeutics. 2019;8(2):282-93.

9. Bajait CS, Pimpalkhute SA, Sontakke SD, Dakhale GN, Jaiswal KM, Urade CS. Evaluation of knowledge, attitude and practice of rational use of medicines among clinicians in a tertiary care teaching hospital. Int $\mathbf{J}$ Nutr Pharmacol Neurol Dis 2014;4:153-7.

10. Ganesh Dakhale1*, Sonali Pimpalkhute,2 Chaitali Bajait , Evaluation of Knowledge, Attitude and Practice of Rational use of Medicine Among Interns and Resident Doctors in a Tertiary Care Teaching Hospital , Journal of Young Pharmacists, Vol 8, Issue 2, Apr-Jun, 2016 ,114-117.

11. Hooli TV, Srikanth, Somashekara SC, Suraj B. Knowledge, attitude, practice of rational use of medicines among junior residents in a tertiary care hospital. Int J Basic Clin Pharmacol 2017;6:2001-4.

Cite this article as: Kanthi GR, Prayaga UK. A questionnaire-based survey among clinicians and postgraduates regarding knowledge, awareness and practice of p-drug in Government General Hospital, Rangaraya Medical College, Kakinada. Int J Basic Clin Pharmacol 2020;9:77-80. 